Professor Lindeboom relates functional pathology to organic processes, and Dr. Stokvis offers some convincing results of psychotherapy applied to a wide variety of psychosomatic diseases.

Dutch physicians are extremely well suited to discuss this subject, since their training includes a broad philosophical background which conditions the mind to see life as a 'gestalt.' Thus their approach to scientific problems has much in common with their teutonic neighbours 'weltanschauung' type of thinking. Because of this, they have a special aptitude for co-ordinating isolated theorie into a meaningful picture. For them, psychosomatics is more than a consideration of man as Aristotle's social animal instead of a morbid specimen of complex biology; in this highly original contribution they succeed in integrating into a unified theory such diverse, but nevertheless important, concepts as psychoanalytic 'substitution' and its ethological counterpart 'displacement,' together with anosognosia which is used to explain how insulin therapy helps schizophrenics.

There are many books on psychosomatics; most of them, from slim introductions to corpulent textbooks, comprise an indigestible surfeit of physiological data in which Old Tom's gastric fistula appears with monotonous regularity. This is not such a book. It is a dignified discourse by experts who have sat down in a cool hour to review their specialty, and who summarise their deliberations in the impeccable English of the continental. It purports to be neither a manual nor textbook; it is a thoughtful commentary on an increasingly important aspect of medicine.

L.R.C.H.

\section{NON-VENEREAL SYPHILIS}

\section{A Sociological and Medical Study of Bejel}

By Ellis Herndon Hudson, M.D., D.T.M. \& H., F.A.C.P. Pp. viii +204 , with 8 I illustrations. Edinburgh: E. \& S. Livingstone Ltd. I 957. 3 os.

The author's study of bejel was incidental to his many years' work as a physician at the Presbyterian Board of Foreign Missions' clinic at Deir-ez-Zor on the upper Euphrates in Syria. The result is a book giving a comprehensive description of this disease from every aspect. It is written in clear explanatory style, which could in most parts be understood by non-medical as well as medical readers. As well as his own work on the clinical and public health aspects of bejel, he gives sections on serology and microscopic pathology by experts, and a summary of the work of $T$. B. Turner and D. H. Hollander on the experimental pathology of the disease. This book can be considered a very good account of bejel, except that the author propounds the hypothesis that syphilis, bejel and the other treponeme caused diseases are all one disease whose differing manifestations are the result of the influence of environment, such as personal hygiene, wearing of clothes and way of life of the patient.
There is not sufficient evidence for this belief to receive general support. He propounds this theory in spite of the fact that he himself points out the fundamental difference between venereal syphilis and the non-venereal treponematoses. For example, he stresses the point that congenital, cardiovascular or neuro bejel (or yaws, etc.) never occur, and that syphilis and bejel are known to exist side-by-side without one leading to the other or vice versa. It would seem more likely that venereal syphilis and bejel are separate distinct diseases in their own right, possibly descended from some common ancestor of the distant past.

This book of r 94 pages is well produced and well printed on good paper. There are tables and graphs and 8I excellent photographs of the lesions of bejel. He gives a list of 74 references, of which no less than 26 refer to his own publications. It may be said to his lasting credit that Hudson's work on bejel was one of the main factors which instigated the highly successful World Health Organisation's campaign against the treponematoses in undeveloped countries.

$$
\text { F.J.G.J. }
$$

\section{CORTISONE THERAPY}

\section{Mainly Applied to the Rheumatic Diseases}

By J. H. GLYN, M.A., M.D., M.R.C.P. D.Phys.Med. Pp. $\mathrm{x}+\mathrm{i} 62$. London: Williano Heinemann Ltd. I957. 2 Is.

This book is a comprehensive review of the⿳亠丷厂 present position of steroid therapy. The author has great experience of his subject, gained both in England and America. There are chapters on history, pharmacology, administration, side effects, indications and contra-indications, including nonrheumatic diseases. Finally there is a chapter on local injection of hydrocortisone with details of technique for individual joints, tendons, etc.

Dr. Glyn has a clear readable style and has succeeded well in setting out the evidence for and against steroid therapy. Some of his conclusions may be controversial but these and the problems he poses for future research are stimulating.

This book should be read widely by all physicians; not only specialists in rheumatology.

\section{BRITISH MEDICAL BULLETIN Anaesthesia}

Volume 14, No. I. January, 1958. Pp. 72, N illustrated. London: British Council. 1958 . 20 .

In this excellent symposium, an introduction by Dr. John Gillies on Progress in Anaesthesia is followed by 16 articles which cover a wide range of subjects associated with anaesthesia in both the theoretical and practical fields. It is interesting to note that among the authors are two physicists, two physiologists, a pharmacologist and a biochemist, a 
fact which emphasizes the everyday collaboration which occurs between anaesthetists and workers in the basic medical sciences.

Among the many informative papers are two on induced hypotension, in which Dr. Hale Enderby and Dr. Armstrong Davison put forward respectively the advantages and disadvantages of controlled hypotension in surgery. Dr. ChurchillDavidson contributes a short article on recent developments with the muscular relaxants and Professor Pask provides a lucid paper on carbondioxide homeostasis in anaesthesia.

In an article on the present position of hypothermia in surgery, Dr. B. G. B. Lucas includes a section on the treatment of cardiac arrest and ventricular fibrillation which should be of interest to all anaesthetists and surgeons, whether or not they make use of hypothermic techniques.

The principles underlying the treatment of paralytic poliomyelitis and tetanus are considered in a paper by Dr. Ronald Woolmer on the treatment of respiratory inadequacy.

The reviewer recommends this symposium to all anaesthetists, and younger anaesthetists who are studying for higher diplomas will find it of inestimable value.

C.C.C.

\section{POLYMYOSITIS}

By John N. Walton, M.D., M.R.C.P., and Raymond D. Adams, M.D. Pp. $x \div 270$, with 47 illustrations. Edinburgh: E. \& S. Livingstone Ltd. 1958. 32s. 6d.

It is only in recent years that the concept of polymyositis as a clinical entity mimicking muscular dystrophy has arisen. This book presents the eridence in favour of considering this condition more frequently in the differential diagnosis of muscular disorders than has been done in the past. A review is first of all given of the literature relating to polymyositis and allied conditions. A clinical and pathological analysis is then made on the basis of to patients all but four of whom were personally examined by the authors. The clinical picture is comprehensively dealt with, the results of relevant investigations such as electromyography are assessed and the pathological findings, especially of muscle biopsies are presented. This latter section is given in the detail it deserves and is particularly well illustrated.

Points of interest include the association of polymyositis with malignant disease, the occurrence of myasthenic features in cases otherwise compatible with a diagnosis of polymyositis and the relationship between this condition and other 'collagen' diseases. When the course of the disease is rapid or if the muscle wasting is associated with evidence of more widespread pathology the possibility of polymyositis may well be considered early in the differential diagnosis. The difficulty arises in the chronic case when the authors admit that it may not be possible to make a definite diagnosis of polymyositis on the clinical or pathological features alone but only if the two are combined, and the results of the electromyographic and biochemical tests are used as well. This difficulty is made no less by the fact that the muscles most severely affected in polymyositis and in progressive muscular dystrophy are those of the shoulder and pelvic girdles and the proximal parts of the limbs. However, the importance of making the diagnosis of polymyositis as soon as possible is not an academic one as it is apparent that a significant proportion of patients with this condition respond to steroid therapy.

This book is of considerable interest and is likely to be read with profit by neurologists, paediatricians or anyone interested in the diseases of muscle.

N.S.G.

\section{ANAESTHESIA AND OTOLARYNGOLOGY}

By Donald F. Proctor, M.D. Pp. xv +267 , with 33 illustrations. London: Bailliere, Tindall \& Cox Ltd. I 957 . 56 s.

The author practised Otolaryngology for 15 years, then wholetime Anaesthesia for four years, reverting to ear, nose and throat surgery, as he states: ' in part as a protest against the anachronistic position in which the specialist in anaesthesiology sometimes finds himself.' $\mathrm{He}$ is now Assistant Professor of Otolaryngology at the Johns Hopkins Hospital.

This book has been written, partly, as an aid to mutual understanding between surgeon and anaesthetist of certain problems affecting either or both because, as the author states: "The surgeon who does not want to follow an anaesthetist's advice about anaesthesia is either himself mistaken or he has the wrong anaesthetist.'

The book is divided into four main sections. Section I presents the problems common to the anaesthetist in any field and contains, among others, a chapter on morbidity and mortality associated with ear, nose and throat surgery, and a chapter on medicolegal considerations in the U.S.A. It is interesting to note that the author uses intramuscular barbiturates for premedication in preference to opiates and their allied drugs so widely used in this country. Section II contains methods of general anaesthesia in ear, nose and throat surgery, and Section III contains the local anaesthetic methods used in this field. Section IV contains certain aspects of respiratory assistance and resuscitation which may become the responsibility of either anaesthetist or surgeon. A very good chapter on tracheotomy and its associated problems occurs in this section, as does an interesting chapter on the controversial subject of respiratory resuscitation in the newborn.

There are 33 illustrations, some being photographs, and the remainder clearly executed drawings, including a full-page illustration of the Holger Nielsen technique of artificial respiration. Each chapter ends with a comprehensive list of references, and the quality of paper and print is good. 